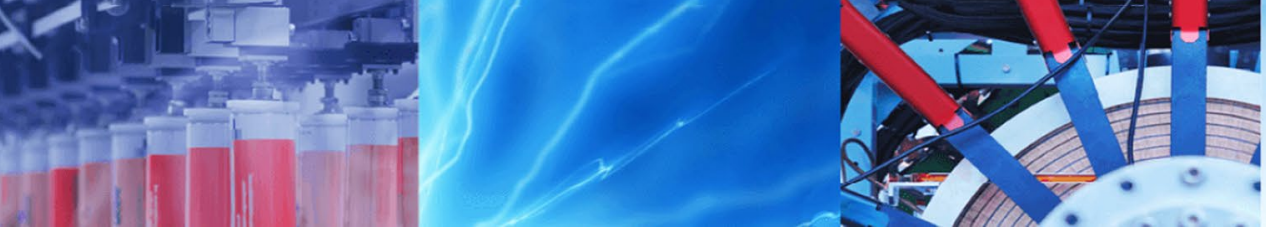

Research Article

\title{
Transient light emission from the silicothermic reduction of magnesium oxide with potential for monitoring intermediate compound formation and decay
}

\author{
Tim Gebensleben $^{1}$ (D) $\cdot$ Verena Becker $^{1}$ (D) Jörg August Becker ${ }^{1}$ (I)
}

Received: 8 July 2019 / Accepted: 29 January 2020 / Published online: 13 February 2020

(c) Springer Nature Switzerland AG 2020

\begin{abstract}
Small silicon samples were brought into contact with magnesium oxide substrate plates and heated under vacuum. At heating temperatures above $1400 \mathrm{~K}$, a transient light emission effect in the $\mathrm{Si} / \mathrm{MgO}$ interface was observed. The changes in sample brightness are likely caused by a thermal effect. Typically the sample temperature decreases gradually by $40-80 \mathrm{~K}$ and is followed by a very fast rise in temperature. The light emission effect may be correlated to the transient formation and decomposition of an inhibiting layer of magnesium silicate and the endothermic formation of gaseous silicon oxide. Tempering a silicon sample on a magnesium oxide plate for several hours produced an etch pit in the substrate material from which the silicon sample split off during the cooling phase. The etch pit was investigated via electron microscopy. EDXS analysis of the finely structured surface of the reaction zone reports a composition of $2 / 1 / 5(\mathrm{Mg} / \mathrm{Si} / \mathrm{O})$. A crosssection of the same area reveals a thin layer of reaction products on top of the substrate material.
\end{abstract}

Keywords Pidgeon process · Reaction interface · Reaction layer · Light emission · Silicothermic process · Silicon · Monitoring of intermediates

\section{Introduction}

With its low density of $1.74 \mathrm{~g} / \mathrm{cm}^{3}$, magnesium is the lightest construction metal produced industrially on a worldwide scale [1, 2]. Magnesium and magnesium-aluminum-alloys, the latter consuming up to fifty percent of the yearly magnesium production, are important materials in the aviation- and automotive-industry, critical for the construction of metal castings and other lightweight parts [2, 3]. In 2018, magnesium metal has been classified as a "critical mineral" by the U.S. Department of the Interior following Executive Order 13817, seeking to establish "A
Federal Strategy to Ensure Secure and Reliable Supplies of Critical Minerals" [3].

The global primary production of magnesium is dominated by China. In 2018, the country produced $800 \times 10^{3}$ metric tons of the estimated $970 \times 10^{3}$ metric tons manufactured worldwide (not counting U.S. domestic production for which data is being withheld) [3].

Despite the demand for magnesium on the rise, especially due to the automotive industry seeking to improve on lightweight-designs in order to comply with fuel efficiency standards, the production in China has seen a decline from 2017, where the country produced $930 \times 10^{3}$ metric tons of magnesium [3]. While there is no shortage

Electronic supplementary material The online version of this article (https://doi.org/10.1007/s42452-020-2126-4) contains supplementary material, which is available to authorized users.

Tim Gebensleben, tim.gebensleben@pci.uni-hannover.de; Verena Becker, verena.becker@pci.uni-hannover.de; Jörg August Becker, joerg-august.becker@pci.uni-hannover.de $\left.\right|^{1}$ Institut für Physikalische Chemie und Elektrochemie, Gottfried Wilhelm Leibniz Universität, Callinstr. 3-3A, 30167 Hannover, Germany. 
of raw materials - magnesium is contained in large quantities in seawater and minerals such as dolomite and serpentine-the primary method of magnesium production in China known as the Pidgeon process comes with high energy costs and is increasingly subject to environmental regulations $[3,4]$. The central step of the Pidgeon process is the silicothermic reduction of magnesium oxide (MgO) with silicon

$2 \mathrm{MgO}(\mathrm{s})+\mathrm{Si}(\mathrm{s}) \rightleftharpoons 2 \mathrm{Mg}(\mathrm{g})+\mathrm{SiO}_{2}(\mathrm{~s})$

producing solid $\mathrm{SiO}_{2}$ and gaseous magnesium as the only volatile component which is then distilled from the reactor. Despite no greenhouse gases being emitted in reaction (1), the process as first systematically described by Toguri and Pidgeon uses the raw materials FeSi (ferrosilicon) and ( $\mathrm{Ca}, \mathrm{Mg}) \mathrm{CO}_{3}$ (dolomite) and starts with the calcination of the dolomite to $\mathrm{MgO}$ and $\mathrm{CaO}$ [5]. The global warming impact of $\mathrm{CO}_{2}$ released in this process has been studied in detail by Ramakrishnan and Koltun and is estimated to be $60 \%$ higher than the impact of Chinese aluminum production [4].

Pidgeon conducted further studies on the thermodynamic equilibria in the silicothermic reduction of calcined dolomite and on the reaction between pure magnesium oxide and silicon [6, 7]. More recent numerical studies discuss the impact of the heat transfer on magnesium as well as the reaction kinetics in the context of the Pidgeon process and propose refined reaction models [8]. Despite the importance of reaction (1) for the global manufacturing industry, there have been very few attempts to study the reduction process in situ by means of physicochemical experiments, partly due to the difficulty of observing reaction-interfaces at high temperatures. One of the few works allowing for the in situ observation of reaction-interfaces has been conducted by Alphei et al., who reported on the setup and application of Auger electron spectroscopy (AES) in the context of reactive wetting experiments at high temperatures [9]. The high-temperature Auger electron spectrometer (HTAES) has been applied to study the reactive wetting of silicon droplets on quartz and $\mathrm{MgO}$ substrates at $1700 \mathrm{~K}$ [9]. During the experiment, previously wetted areas of the substrate material can be analyzed from above by means of the Auger spectrometer and the heating and wetting processes can be observed from below via a camera-mounted microscope. On MgO, silicon droplets perform concentric spreading motions and lateral movements, temporarily exposing previously wetted areas of the substrate. The authors report oxygen-bound silicon in de-wetted areas of $\mathrm{MgO}$ substrates and estimate the surface composition ratio of $\mathrm{Mg} / \mathrm{Si} / \mathrm{O}$ at 4/1/8 [9]. The setup is depicted in Fig. 1.

On MgO substrates, Alphei noticed transient dips and jumps of perceived sample brightness in the $\mathrm{Si} / \mathrm{MgO}$ interface during the heating phase which can colloquially be described as the sample blinking. In order to quantify the effect, experiments documenting the sample brightness at constant heater settings were prepared. The effect appears to be most pronounced for small samples. Initially, irregularly shaped silicon splinters with a weight of 20-100 $\mu \mathrm{g}$ were used (Figs. 2 and 3).

Jumps from low to high brightness (intensity) occur suddenly and are usually preceded by a phase of decreasing intensity, for example between $1800 \mathrm{~ms}$ and $3200 \mathrm{~ms}$ in Fig. 2, which is then interrupted by another quick jump in intensity. Sometimes jumps are in quick succession such
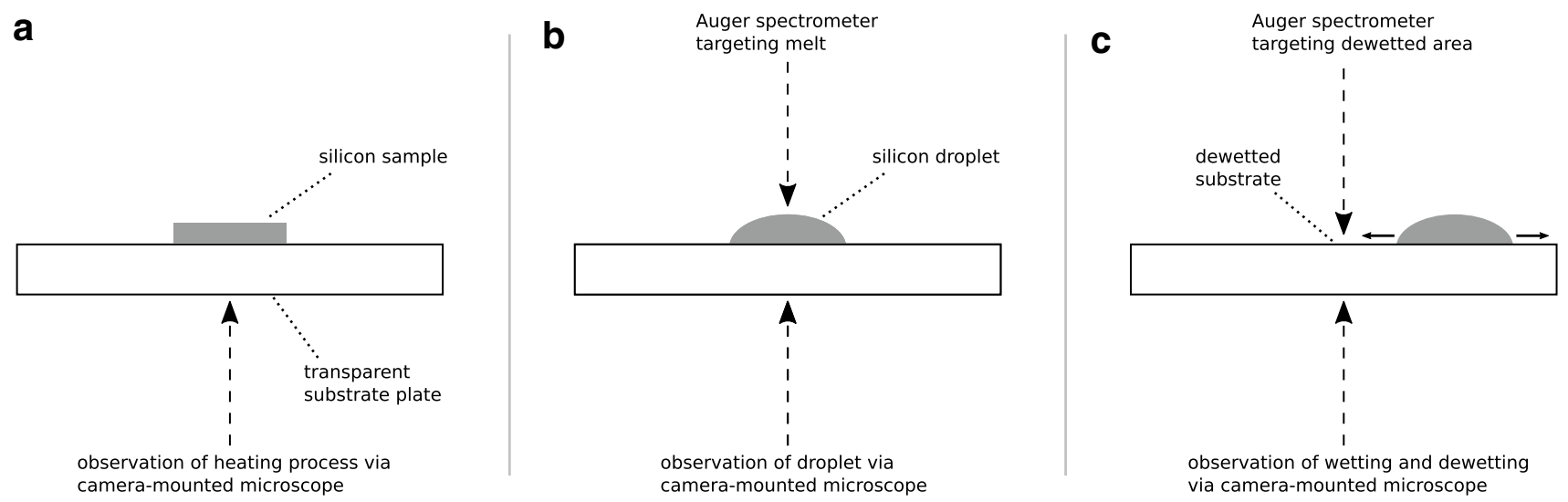

Fig. 1 Sample observation in HTAES setup developed by Alphei et al. [9]. a A silicon sample $(20-100 \mu \mathrm{g})$ is placed on a quartz or $\mathrm{MgO}$ substrate plate. The heating process can be controlled from below via a camera-mounted microscope. b Targeting of silicon melt via $A E S$ and observation of the reaction interface through the substrate. c The silicon droplet undergoes wetting and dewetting phases and performs lateral movements (horizontal arrows). Previously wetted areas can be analyzed in situ with the Auger spectrometer 

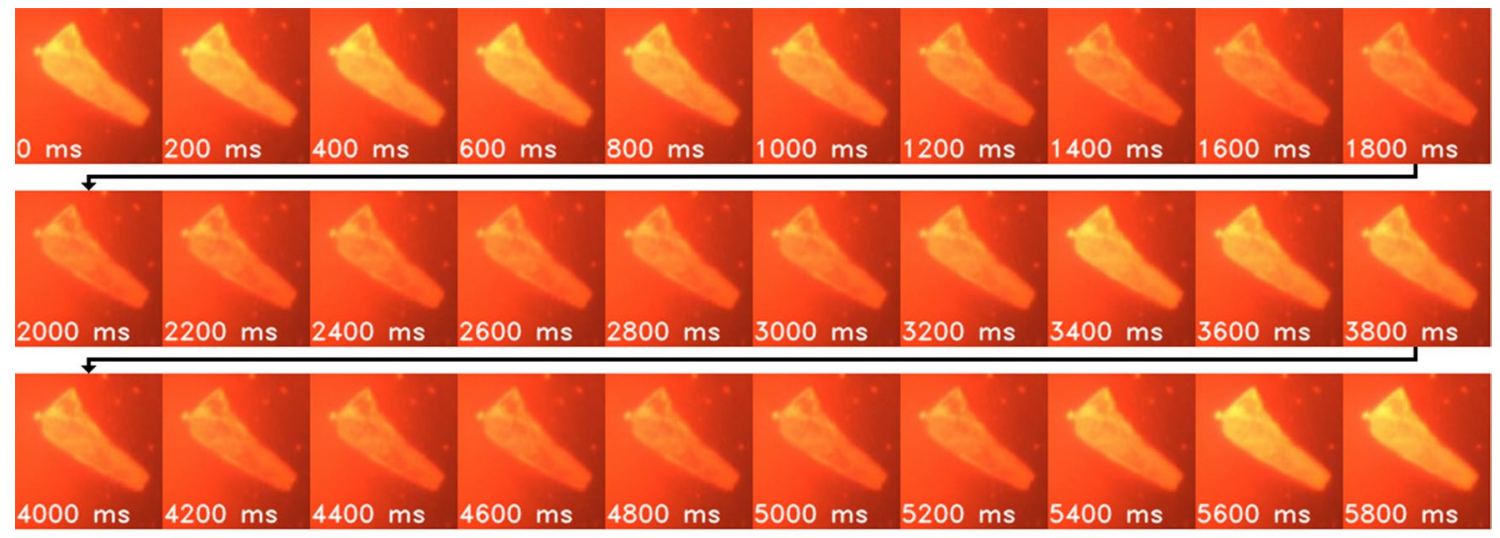

$500 \mu \mathrm{m}$

Fig. 2 Time series of a single heated silicon sample $(40 \mu \mathrm{g})$ on an $\mathrm{MgO}$ substrate plate close to the melting point at $1687 \mathrm{~K}$. The sample is observed through the transparent substrate from below as depicted in Fig. 1. Each sub-image is annotated with the time passed since an arbitrary starting point at zero milliseconds. Each row of sub-images offers a temporal resolution of $200 \mathrm{~ms}$ while sub-images in the same column are $2 \mathrm{~s}$ apart. Sudden jumps in brightness can be observed at $3400 \mathrm{~ms}, 5400 \mathrm{~ms}$, and $5600 \mathrm{~ms}$. An animated version of this figure is available in Online Resource 1

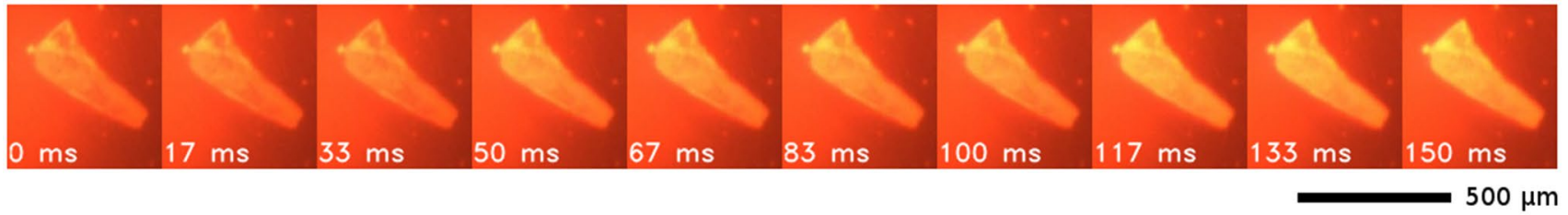

Fig. 3 Time series of the sample depicted in Fig. 2 at higher temporal resolution. Each sub-image is annotated with the time passed since an arbitrary starting point at zero milliseconds. Sudden jumps

as depicted at timestamp $5400 \mathrm{~ms}$ and $5600 \mathrm{~ms}$. Our current setup allows recording the sample at 60 frames per second. A frame-by-frame time series with two sudden jumps in intensity is illustrated in Fig. 3.

This work focuses on the experimental study of the light emission effects from the $\mathrm{Si} / \mathrm{MgO}$ interface and discusses a possible set of reactions which may be related to the transient nature of the effect. Details of the reaction mechanism remain unclear.

\section{Experimental setup}

The experiment is conducted in the vacuum chamber of the HTAES setup described in detail by Alphei et al. [9]. The Auger spectrometer is not used in the experiment discussed in this work and has been shielded from gaseous reaction products such as $\mathrm{Mg}(\mathrm{g})$ and $\mathrm{SiO}(\mathrm{g})$ with a blind made of molybdenum foil. Previous experiments showed that gaseous magnesium can damage the spectrometer's ion optics and cause signal drift. Extensive in situ study of the reaction between magnesium oxide and silicon by in intensity can be observed at $50 \mathrm{~ms}$ and $117 \mathrm{~ms}$. An animated version of this figure is available in Online Resource 2

means of Auger spectroscopy would require a complete refit of the experimental setup with effective measures to protect the ion optics from metallic gases. The observation and recording of the sample from below as depicted in Fig. 1 remains unimpaired by shielding the spectrometer. Vibrations affecting the sample holder were reduced by attaching several heavy weights to the vacuum chamber from the outside. This was necessary in order to minimize movement of the sample in the video recording such that its intensity can be sampled at a constant position with respect to the image coordinates.

The chamber is pumped with two scrolls pumps (Varian SH-110, Varian TriScroll 300) and four turbomolecular pumps (Agilent TwisTorr 84 FS, Varian TV 301 Navigator, Varian TV 70 LP, Varian TV 551 Navigator). Typical pressures during reaction conditions range from $10^{-4}$ to $10^{-5} \mathrm{~Pa}$.

An MgO substrate plate of size $10 \mathrm{~mm} \times 10 \mathrm{~mm} \times 0.5 \mathrm{~mm}$ and orientation $\langle 100\rangle$ is cleaned with ethanol for $10 \mathrm{~min}$ in an ultrasonic bath. The silicon sample is placed on the clean substrate afterward. The substrate plate resides in a custom boron nitride sample holder which is placed on a boron nitride heater (Momentive BORALECTRIC) as shown 


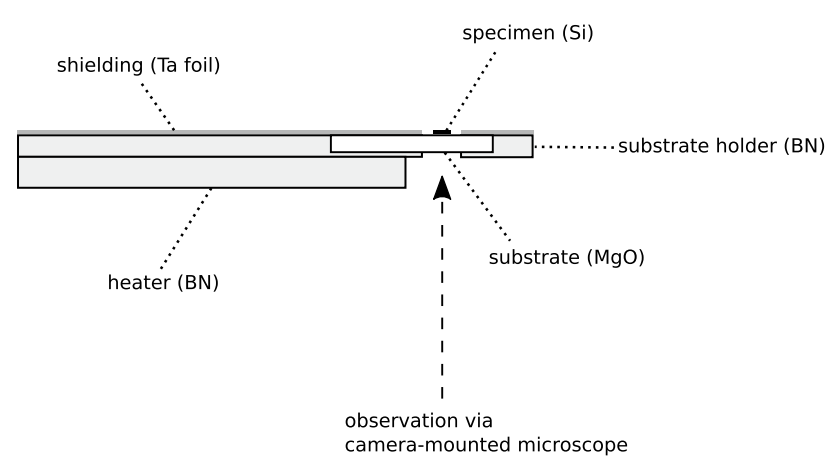

Fig. 4 Placement and observation of a silicon sample on an $\mathrm{MgO}$ substrate. The BN sample holder is fixated on a BN heater plate. The underside of the sample holder offers a $4 \mathrm{~mm}$ wide hole such that observation of the sample through a sapphire window (not depicted) and the transparent substrate material is possible (dashed arrow). Details on sample holder fixation, shielding, cooling, and electrical wiring have been omitted and are available in the previous work on the HTAES setup [9]

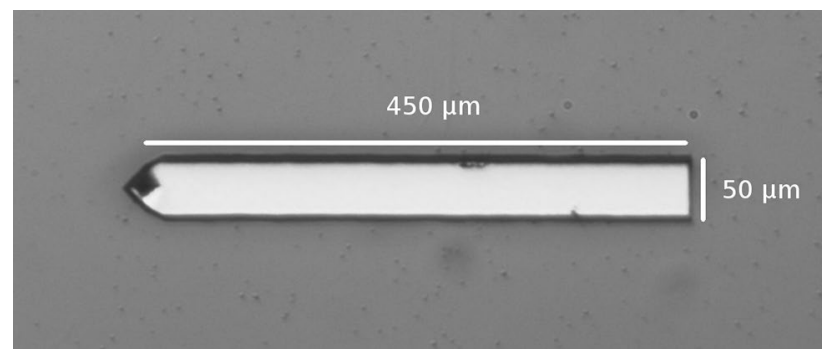

Fig. 5 Optical microscope (Zeiss JENAVERT) image of silicon cantilever broken off from AFM probe body and placed on an MgO substrate plate. Cantilevers are typically $450 \mu \mathrm{m}$ long, $50 \mu \mathrm{m}$ wide and $2 \mu \mathrm{m}$ thick. Cantilevers not breaking off at their base on the AFM probe body during sample preparation can be shorter

in Fig. 4. The sample can be observed through a sapphire window with a camera-microscope (AlliedVision Guppy F-146 mounted on Novex optical microscope).

After preliminary experiments reproducing the light emission effect with small, irregularly shaped silicon pieces (30-100 $\mu \mathrm{g}$ ) such as shown in Figs. 2 and 3 the experiment has been prepared with a silicon cantilever as used in atomic force microscopy (AFM). The cantilever is used in order to ensure a regular, fixed sample geometry and uniform contact with the substrate material. The AFM probes (NANOSENSORS PPP-CONT) used in sample preparation consist of a silicon cantilever of size $450 \mu \mathrm{m} \times 50 \mu \mathrm{m} \times 2 \mu \mathrm{m}$ (mean values) attached to a larger silicon body. During sample preparation, the cantilever is broken off from the silicon body and placed on an MgO substrate plate (Fig. 5).

Cantilever samples were either recorded at different heater settings in order to document the transient light emission effect or tempered for $5 \mathrm{~h}$ at constant heating temperature.

\section{Results}

The transient light emission effect was successfully repeated with a silicon cantilever sample. Figures 6 and 7 show time series analogous to Figs. 2 and 3.

The intensity of the cantilever has been sampled at four different heater settings. Transient decreases and jumps in intensity are more frequent at higher temperatures. Moreover, sometimes jumps in intensity are too fast to fully capture at our current sample rate of $60 \mathrm{~Hz}$, especially at high temperatures.

The sample temperature was obtained pyrometrically using Planck's law and taking the camera's quantum efficiency into account. The emissivity of silicon has been treated as constant over the temperature range 1300-1687 $\mathrm{K}$ and over the visible region [10-13]. The green and blue channel intensities are very low even at temperatures close to the melting point of silicon. At the highest heater setting, the temperature difference corresponding to exemplary jumps in intensity can be calculated and compared for all channels. Obtaining similar values across channels with a deviation of approximately five percent strongly suggests that the transient light emission is caused by a thermal effect. Further temperature values have been calculated on the basis of the red channel as it offers sufficient intensity at all heater settings. The results of the intensity sampling at different heater settings are summarized in Fig. 8. The mean temperature of the sample typically decreases by 40-80 Kelvin before rising again.

Very fast jumps in intensity are more frequent and more pronounced at higher heating temperatures such as depicted in sub-figure $1 \mathrm{~b}$ of Fig. 8 . The same data is shown at higher resolution in Fig. 9, with some prominent jumps in intensity annotated and quantified. The figure also reveals dips in intensity that are too fast to be fully captured at a $60 \mathrm{~Hz}$ sample rate, but the most pronounced sudden changes in intensity occur going from low to high intensity values.

Tempering a cantilever sample at high temperatures over several hours results in characteristic, cantilevershaped etch pits in the $\mathrm{MgO}$ substrate. The cantilever typically splits off from the substrate during the cooling phase, exposing the area of reaction as depicted in Fig. 10. The surface of the reaction zone is shown at higher resolution in Fig. 11. A cross-section along the substrate area and area of reaction has been obtained via Focused lon Beam (FIB) technology and reveals a thin layer of reaction products on top of the substrate material with a thickness of approximately $250 \mathrm{~nm}$ (Fig. 12). Qualitative EDXS analysis 

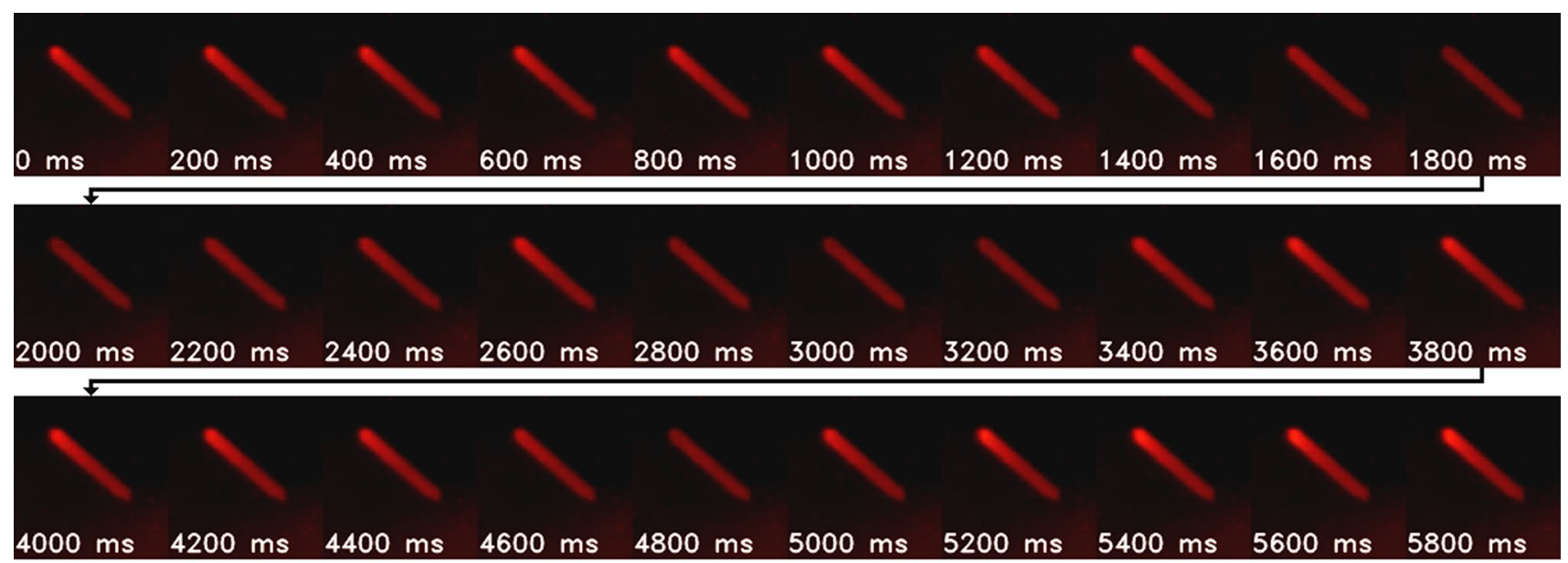

$4000 \mathrm{~ms} 4200 \mathrm{~ms} 4400 \mathrm{~ms} \quad 4600 \mathrm{~ms} \quad 4800 \mathrm{~ms} \quad 5000 \mathrm{~ms} \quad 5200 \mathrm{~ms} \quad 5400 \mathrm{~ms} \quad 5600 \mathrm{~ms} \quad 5800 \mathrm{~ms}$

Fig. 6 Time series of a single heated silicon cantilever on an $\mathrm{MgO}$ substrate plate. Each sub-image is annotated with the time passed since an arbitrary starting point at zero milliseconds. Each row of sub-images offers a temporal resolution of $200 \mathrm{~ms}$ while sub- images in the same column are $2 \mathrm{~s}$ apart. Sudden jumps in intensity can be observed for example at $2600 \mathrm{~ms}, 3400 \mathrm{~ms}$, and $5000 \mathrm{~ms}$. Brightness and contrast have been adjusted to improve visibility. An animated version of this figure is available in Online Resource 3

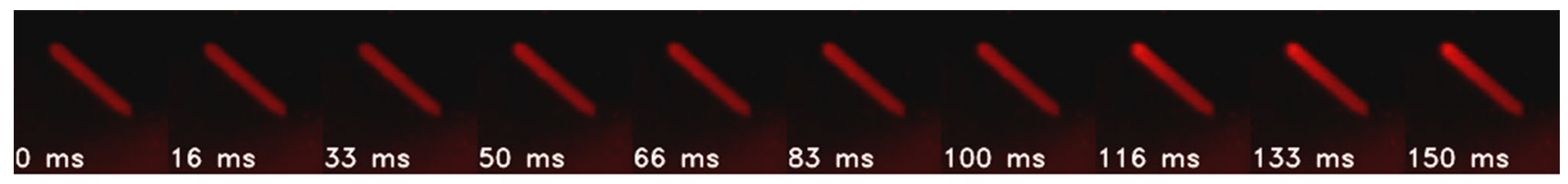

Fig. 7 Time series of the sample depicted in Fig. 6 at higher temporal resolution. Each sub-image is annotated with the time passed since an arbitrary starting point at zero milliseconds. A sudden

of the layer indicates the presence of magnesium, silicon, and oxygen.

The etch pit contains silicon fragments from the underside of the cantilever. Cavities corresponding to these fragments can be found on cantilever pieces scattered across the substrate. The surface area of the etch pit consists of a finely structured layer of reaction product containing small rounded areas which are smoother than the surrounding surface (Fig. 11). It is possible that the smooth areas were formed due to the cantilever ripping off the top layer of the surface in some locations when splitting off from the etch pit during cooling. The SEM offers an EDXS unit which reports a composition of approximately $2 / 1 / 5(\mathrm{Mg} / \mathrm{Si} / \mathrm{O})$ on the surface of the etch pit.

\section{Discussion}

The composition of $2 / 1 / 5(\mathrm{Mg} / \mathrm{Si} / \mathrm{O})$ of the reaction product layer covering the etch pit is close to the composition expected for a layer of pure $\mathrm{Mg}_{2} \mathrm{SiO}_{4}$. Excess atmospheric jump in intensity can be observed at $116 \mathrm{~ms}$. Brightness and contrast have been adjusted to improve visibility. An animated version of this figure is available in Online Resource 4

oxygen may have attached to the finely structured surface layer under ex situ conditions. The composition of 4/1/8 ( $\mathrm{Mg} / \mathrm{Si} / \mathrm{O})$ estimated by Alphei from targeting areas of the substrate previously wetted by liquid silicon with in situ Auger spectroscopy may be a mixture of magnesium oxide and magnesium silicates.

The formation of $\mathrm{Mg}_{2} \mathrm{SiO}_{4}$ in the reaction of magnesium oxide and silicon is well known. Toguri and Pidgeon [7] showed that the model reaction (1) is not followed in practice. Instead, magnesium silicate forms via

$4 \mathrm{MgO}(\mathrm{s})+\mathrm{Si}(\mathrm{s}) \rightleftharpoons 2 \mathrm{Mg}(\mathrm{g})+\mathrm{Mg}_{2} \mathrm{SiO}_{4}(\mathrm{~s})$.

However, Eq. (2) still does not fully capture the reaction of magnesium oxide and silicon at high temperatures. Thermal gravimetric analysis showed a strong excess loss of weight in the reactants setting in at approximately $1573 \mathrm{~K}$ which cannot be accounted for by reaction (2) alone [7]. Pidgeon suggests the formation of gaseous SiO described by an overall reaction which can be formulated as 

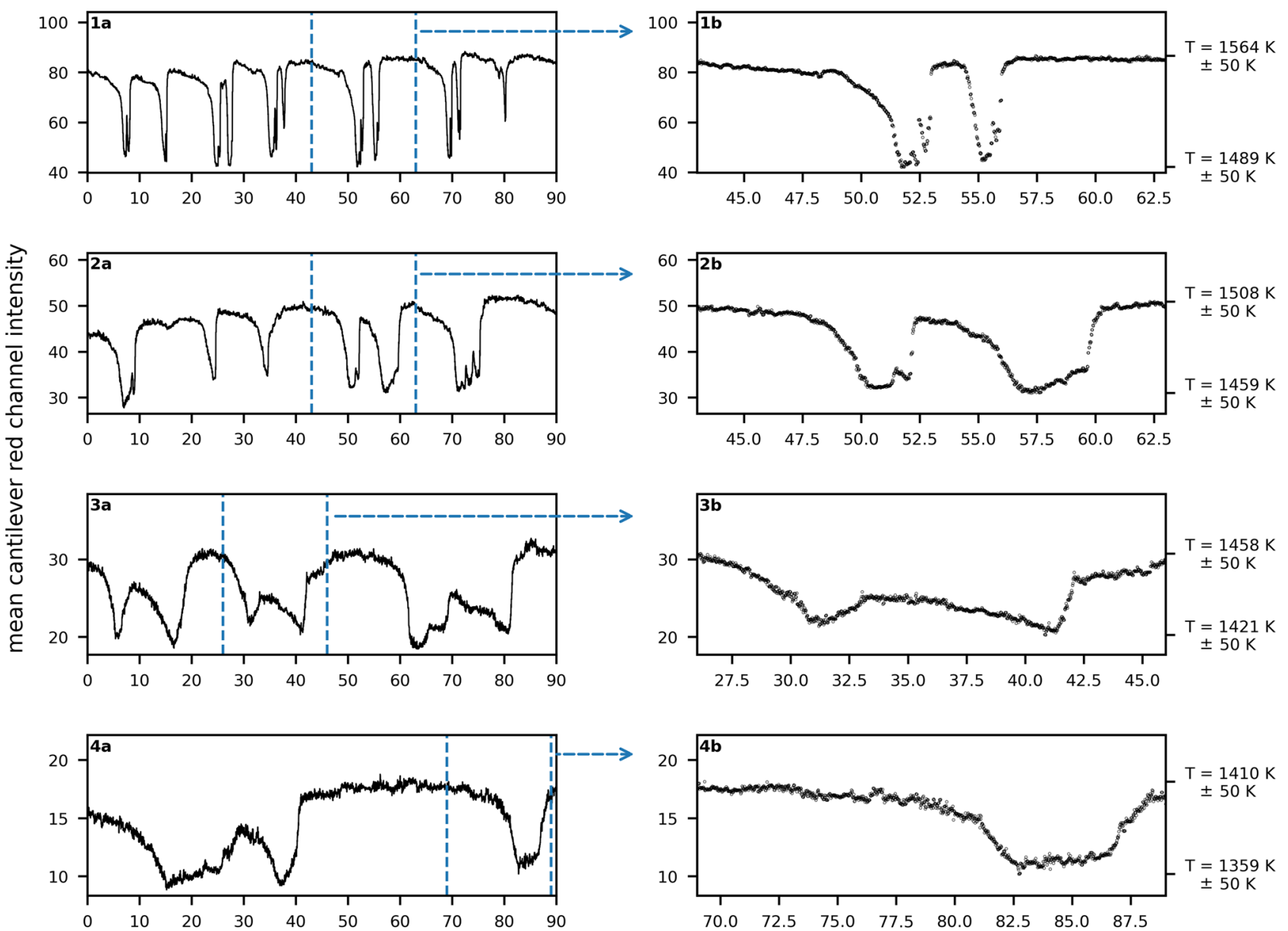

time in seconds

Fig. 8 Mean cantilever red channel intensity at four different heater settings and pyrometrically determined mean cantilever temperatures. Each sub-figure in the left column (1a-4a) shows the mean intensity over an interval of $90 \mathrm{~s}$ from an arbitrary starting point at zero seconds. The blue dashed lines mark regions which are depicted at higher temporal resolution in the sub-figures to the right (1b-4b). These figures are annotated to the right with pyro-

$$
\begin{gathered}
\mathrm{MgO}(\mathrm{s})+\frac{n+1}{4 n+1} \mathrm{Si}(\mathrm{s}) \rightleftharpoons \frac{n}{4 n+1} \mathrm{Mg}_{2} \mathrm{SiO}_{4}(\mathrm{~s}) \\
+\frac{2 n+1}{4 n+1} \mathrm{Mg}(\mathrm{g})+\frac{1}{4 n+1} \mathrm{SiO}(\mathrm{g})
\end{gathered}
$$

by use of a parameter $n$ between zero and infinity [7]. The boundary cases are

$\mathrm{MgO}(\mathrm{s})+\mathrm{Si}(\mathrm{s}) \rightleftharpoons \mathrm{Mg}(\mathrm{g})+\mathrm{SiO}(\mathrm{g})$

for $n=0$ and reaction (2) for $n \rightarrow \infty$. The parameter $n$ can be related to the molar fraction $x_{\mathrm{SiO}}=\frac{1}{2 n+2}$ of $\mathrm{SiO}(\mathrm{g})$ in the gas phase with a theoretical maximum of $1 / 2$ according to reaction (4) and becoming non-negligible at $1573 \mathrm{~K}$ in the thermogravimetric experiments conducted by Pidgeon. metrically determined temperatures corresponding to the maximum and minimum intensity values. Sample data points are not connected in the right column of sub-figures such that breaks in the plot visualize dips and jumps in intensity too fast to fully capture at our current sample rate of $60 \mathrm{~Hz}$. Particularly prominent jumps in intensity can be observed in sub-figure $\mathbf{1} \mathbf{b}$. These jumps are examined further in Fig. 9

The entropy driven formation of gaseous $\mathrm{SiO}$ can be observed for silicon in contact with metal oxides with in situ mass spectrometry but requires liquid silicon from larger samples [14]. The calculated temperature for the highest heater setting (Fig. 8) is just below the temperature where the excess weight loss due to reaction (4) becomes noticeable in Pidgeon's experiments. It is possible that in our setup the endothermic formation of $\mathrm{SiO}$ sets in at lower temperatures and is of transient nature, temporarily cooling the sample and explaining the recurring decreases in emission intensity. Reaction (4) may be inhibited by a layer of $\mathrm{Mg}_{2} \mathrm{SiO}_{4}$ forming between the silicon sample and the substrate, expected to be much thinner 
Fig. 9 Data from sub-figure $1 \mathrm{~b}$ of Fig. 8 at higher resolution with four prominent jumps in intensity annotated in blue. Each black bullet represents one point of intensity sample data at a sample rate of $60 \mathrm{~Hz}$. The jumps (1), (2), (3) and (4) correspond to the following increases in temperature: (1) $25 \mathrm{~K},(2) 23 \mathrm{~K},(3) 15 \mathrm{~K},(4) 13 \mathrm{~K}$. Confidence for temperature differences is $\pm 5 \mathrm{~K}$

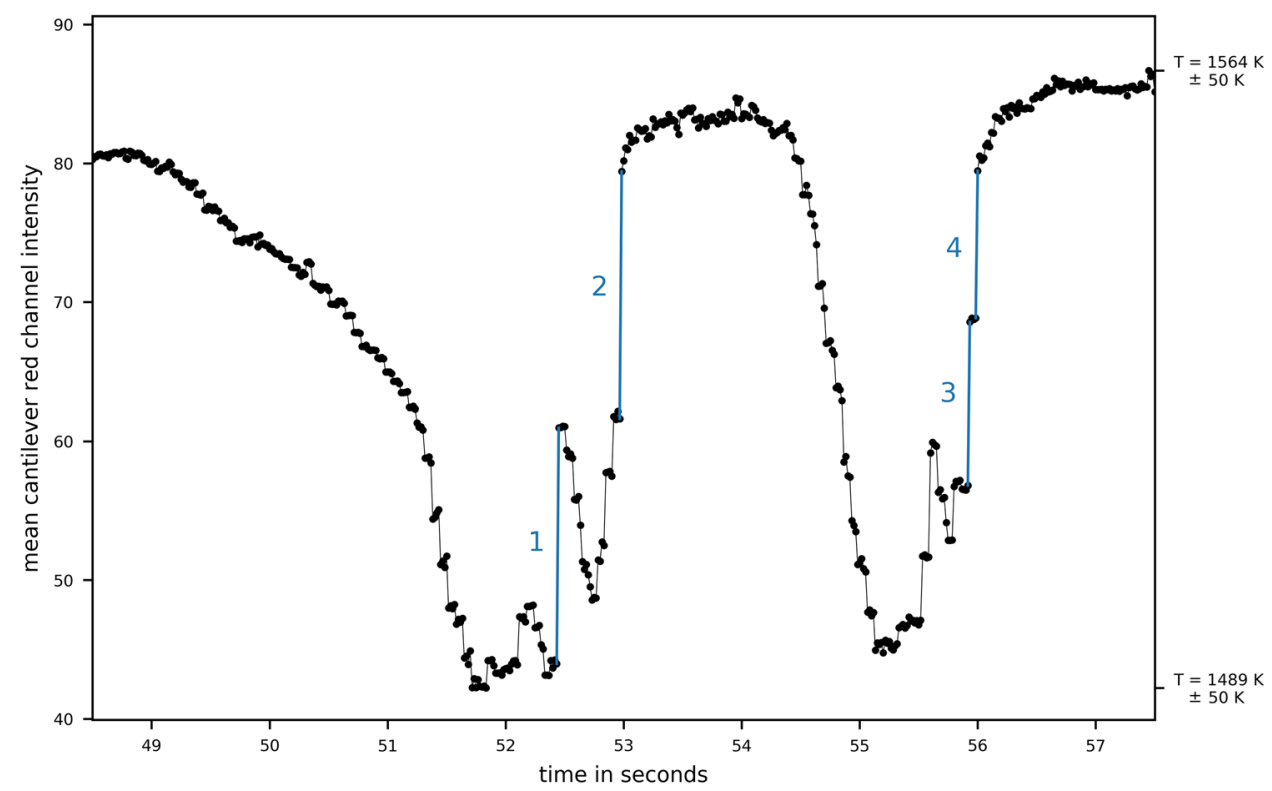

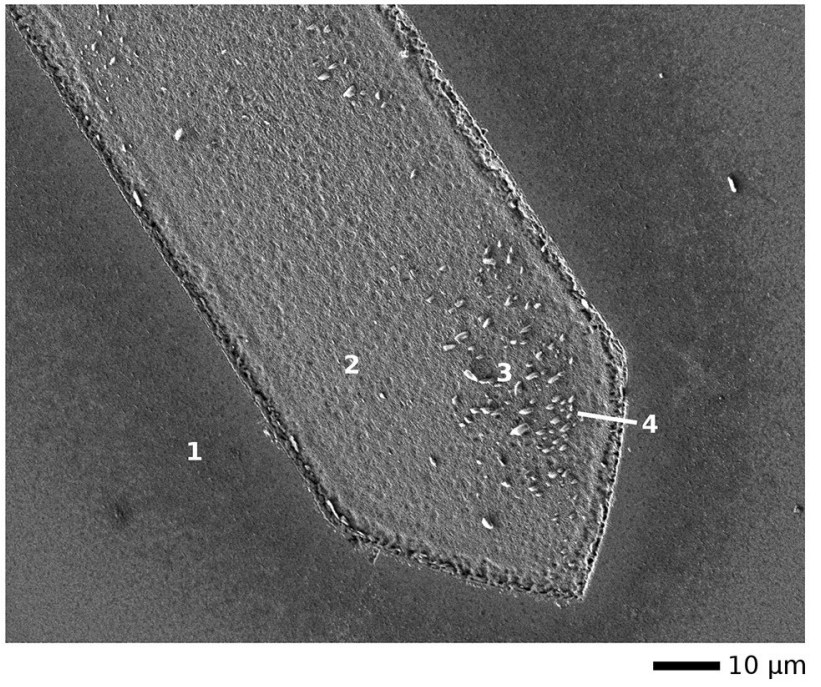

Fig. 10 SEM image (JEOL-JSM-6700F) of reaction zone after tempering a cantilever for $5 \mathrm{~h}$ on an $\mathrm{MgO}$ substrate plate at approximately $1400 \mathrm{~K}$. The cantilever splits off from the substrate in the cooling phase, exposing a cantilever-shaped etch pit. (1) $\mathrm{MgO}$ substrate, (2) Etch pit, area of contact between cantilever and $\mathrm{MgO}$ substrate during tempering. (3) Remaining fragments of silicon from the underside of the cantilever. (4) The cross-section of the surface obtained via Focused Ion Beam was cut along the white line (Fig. 12)

than the $250 \mathrm{~nm}$ formed after $5 \mathrm{~h}$ of tempering and depicted in Fig. 12. The layer may decompose via

$\mathrm{Mg}_{2} \mathrm{SiO}_{4}(\mathrm{~s})+3 \mathrm{Si}(\mathrm{s}) \rightleftharpoons 2 \mathrm{Mg}(\mathrm{g})+4 \mathrm{SiO}(\mathrm{g})$

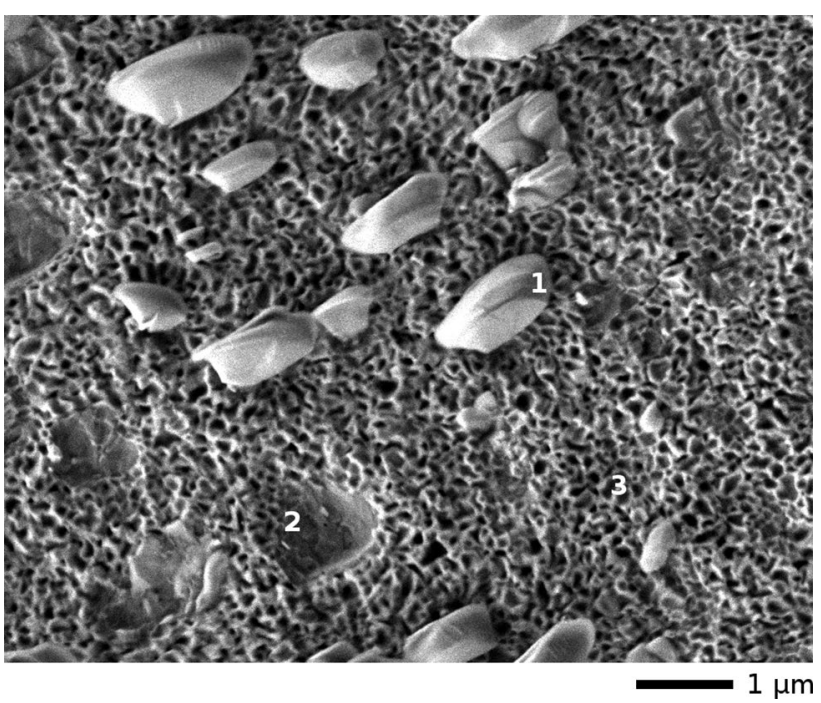

Fig. 11 SEM image (JEOL-JSM-6700F) of etch pit surface as shown in Fig. 10 at a higher resolution. (1) Small fragment of remaining silicon from the underside of the cantilever. (2) The surface contains several small, rounded areas which appear smoother than the surrounding surface. (3) Finely structured surface area of etch pit with an $\mathrm{Mg} / \mathrm{Si} / \mathrm{O}$ ratio of approximately $2 / 1 / 5$ measured with EDXS

providing a cooling effect itself and enabling reaction (4). Once the formation of $\mathrm{Mg}_{2} \mathrm{SiO}_{4}$ sets in again according to reaction (2) the formation of $\mathrm{SiO}$ becomes inhibited and the temperature rises again. A detailed mechanism explaining the transient formation and decomposition of an $\mathrm{Mg}_{2} \mathrm{SiO}_{4}$ layer is unknown. 


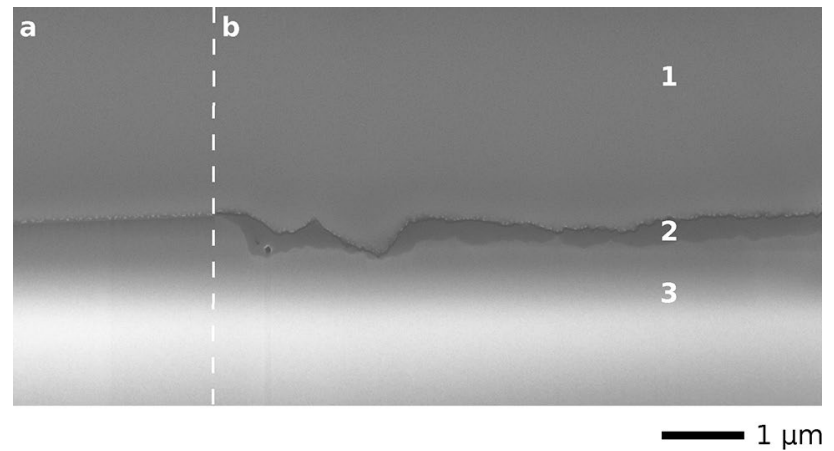

Fig. 12 SEM image (Zeiss AURIGA) of surface cross-section obtained via Focused Ion Beam. The cross-section runs along the white line marked with the number 4 in Fig. 10. White dashed line: separator between areas a and b. a Area of the cross-section outside of the etch pit. $b$ Area of the cross-section inside the etch pit. (1) Sacrificial platinum layer administered to protect the surface from the Focused lon Beam. (2) Thin layer of reaction products covering the etch pit. The thickness of the layer at this location is approximately $250 \mathrm{~nm}$. (3) MgO substrate. The elevated brightness in the lower half of the image is due to the insulator $\mathrm{MgO}$ being subject to electric charging effects

\section{Conclusions}

A transient light emission effect has been observed for small silicon samples on magnesium oxide substrates. It is likely that the effect is thermal. The mean sample temperature has been determined pyrometrically and typically decreases by $40-80 \mathrm{~K}$ before rising again. Increases in temperature can occur very rapidly at temperatures around and above $1400 \mathrm{~K}$. The decrease in temperature was discussed in relation to the transient formation of gaseous SiO cooling the sample, the formation possibly being inhibited by a thin layer of $\mathrm{Mg}_{2} \mathrm{SiO}_{4}$.

Acknowledgements We thank the group of Professor Armin Feldhoff for providing access to the scanning electron microscope JEOL-JSM$6700 \mathrm{~F}$ used to investigate the sample surfaces and the generous and regular support in obtaining high-quality images. We thank the Institut für Werkstoffkunde of the Leibniz Universität Hannover and Dr.-Ing. Torsten Heidenblut for providing access to the scanning electron microscope Zeiss AURIGA and for the preparation of the sample cross-section.

\section{Compliance with ethical standards}

Conflict of interest On behalf of all authors, the corresponding author states that there is no conflict of interest.

\section{References}

1. Lide DR (2003) CRC handbook of chemistry and physics, 84th edn. CRC Press, Boca Raton

2. Binnewies $M$, Finze $M$, Jäckel $M$ et al (2016) Allgemeine und anorganische Chemie. Springer, Berlin

3. Magnesium Statistics and Information. https://www.usgs.gov/ centers/nmic/magnesium-statistics-and-information. Accessed 5 Jun 2019

4. Ramakrishnan S, Koltun P (2004) Global warming impact of the magnesium produced in China using the Pidgeon process. Resour Conserv Recycl 42:49-64. https://doi.org/10.1016/j.resco nrec.2004.02.003

5. Toguri JM, Pidgeon LM (1962) High-temperature studies of metallurgical processes: part II. The thermal reduction of calcined dolomite with silicon. Can J Chem 40:1769-1776. https://doi. org/10.1139/v62-271

6. Wynnyckyj JR, Pidgeon LM (1971) Equilibria in the silicothermic reduction of calcined dolomite. Metall Trans 2:979-986. https:// doi.org/10.1007/BF02664228

7. Toguri JM, Pidgeon LM (1961) High-temperature studies of metallurgical processes: part I. The thermal reduction of magnesium oxide with silicon. Can J Chem 39:540-547. https://doi. org/10.1139/v61-065

8. Li RB, Zhang SJ, Guo LJ, Wei JJ (2013) Numerical study of magnesium (Mg) production by the Pidgeon process: impact of heat transfer on Mg reduction process. Int J Heat Mass Transf 59:328337. https://doi.org/10.1016/j.ijheatmasstransfer.2012.09.027

9. Alphei LD, Dobbe C, Becker V, Becker JA (2015) A high-temperature Auger electron spectrometer setup and its application to reactive wetting experiments at $1700 \mathrm{~K}$. J Mater Sci 50:31753182. https://doi.org/10.1007/s10853-015-8879-2

10. Jain SC, Agarwal SK, Borle WN, Tata S (1971) Total emissivity of silicon at high temperatures. J Phys D Appl Phys 4:1207-1209. https://doi.org/10.1088/0022-3727/4/8/323

11. Timans PJ (1993) Emissivity of silicon at elevated temperatures. J Appl Phys 74:6353-6364. https://doi.org/10.1063/1.355159

12. Takasuka E, Tokizaki E, Terashima K, Kimura S (1997) Emissivity of liquid silicon in visible and infrared regions. J Appl Phys 81:6384-6389. https://doi.org/10.1063/1.364418

13. Ravindra NM, Sopori B, Gokce OH et al (2001) Emissivity measurements and modeling of silicon-related materials: an overview. Int J Thermophys 22:1593-1611

14. Wachsmuth D, Gebensleben T, Weiß D et al (2012) SiO gas emission and triple line dynamics of small silicon droplets on quartz. J Cryst Growth 355:122-128. https://doi.org/10.1016/j.jcrys gro.2012.06.044

Publisher's Note Springer Nature remains neutral with regard to jurisdictional claims in published maps and institutional affiliations. 